\title{
分子量分布が狭い高分子流体の分子量と 非ニュートン粘度の関係についで*
}

\author{
中 村 良** 吉 岡 直 哉**
}

\section{On the Relation between the Molecular Weight of Narrow-Distribution Polymers and Their Non-Newtonian Viscosity \\ by}

Ryo NAKAmURA and Naoya YoshiokA

(Faculty of Engineering, Kyoto University, Kyoto)

The non-Newtonian viscosity derived from the previously proposed constitutive equation ${ }^{7)}$ was expressed as follows,

$$
\eta(\gamma)=\int_{0}^{\infty} H(\lambda) \frac{1}{2 \alpha^{2}}[1-A(\alpha)] d \lambda, \quad A(\alpha)=\int_{0}^{\infty} e^{-x-\alpha^{2} x^{2}} d x, \quad \alpha^{2}=\frac{1}{2} \beta \lambda \gamma
$$

where $H(\lambda)$ was the relaxation spectrum and $\lambda, \gamma$, and $\beta$ were the relaxation time, shear rate and a nondimensional parameter of order 1 , respectively. When polymers are approximated in their narrow-distribution $H(\lambda)$ by

$$
H(\lambda)= \begin{cases}\frac{H_{1}}{1-\delta_{0}}, & \lambda_{0} \leqslant \lambda \leqslant \lambda_{1}, \quad \delta_{0}=\frac{\lambda_{0}}{\lambda_{1}} \\ 0 & \text { Otherwise }\end{cases}
$$

the non-Newtonian viscosity calculated from these equations can be superposed as shown in Fig. 1 . If $\lambda_{1}$ is replaced by the natural time $\lambda_{N}$ defined by $\lambda_{N}=\eta(0) J(0)$, which is more directly related to measurable quantities, the reduced shear rate in Fig. 1 becomes

$$
\beta \frac{\delta_{s}}{1+\delta_{0}} \lambda_{N} \gamma
$$

where $J(0)$ is steady-state compliance and $\delta_{s}=1+1.8 \delta_{0}{ }_{0}^{0.86}$.

Prest's data ${ }^{8)}$ of $J(0)$ are expressed in terms of entanglement density $E$ as follows

$$
\frac{J(0)}{J_{R c}}=\frac{1.22 E}{1+0.22 E}, \quad E=\frac{M}{M_{c}} \text { or } \frac{C M}{(C M)_{c}}
$$

where $J_{R c}$ is the Rouse steady-state compliance at the critical molecular weight $M_{c}$. If this experimental equation is used with assumptions that $\beta$ is independent of $M$ and $\delta_{0}^{-1}=E$, the relation between the characteristic time $\lambda_{c h}$ and $M$ is to be expressed as

$$
\lambda_{c h} \propto \frac{\eta(0) E}{1+0.34 E} \text {. }
$$

This is in the same relation as Graessley's, and is applied to the narrow distribution of polydimethyl siloxane melts ${ }^{9)}$ with fairly good agreement as shown in Fig. 2 . The solid line in this figure shows the viscosity curve at $\delta_{0}=1$ in Fig.1.

(Received Jan. 31, 1972)

\section{1 緒言}

従来から，非二ニートン粘度に対する，分子量，濃 度, 分子量分布, 温度などの影響を明確にするため, 換算変数法が用いられている。 その出癹点は Bueche の理論で，換算粘度 $\eta(\gamma) / \eta(0)$ を換算ずり速度 $\lambda_{c h} \dot{\gamma}$ ( $\lambda_{c h}$ は高分子流体の特性緩和時間) に対して点経する と, 分子量, 濃度などによらない一本の master curve

* 原稿受理 昭和 47 年 1 月 31 日

** 正会員 京都大学工学部 京都市左京区吉田本町
が得られることを示唆している，ところで，分子量分 布が異な机ば非二ュートン粘度曲線の形は異なること がわかっている。尔こで，分子量分布が狭い場合のみ について考えると, 特性緩和時間が分子量, 濃度など にどのような依存するかといらことが換算変数法の中 心的課題となる。

(1) Bueche $\begin{gathered}2 \\ \text { (1) }\end{gathered}$ 従来の関係式

$$
\lambda_{c h} \propto \eta(0) M
$$


（2）箱型緩和スペクトルから導びかれる式：箱の幅 が広いとき,

$$
\lambda_{c h} \propto \eta(0)
$$

(3) Strattonの式: 実測值に基づいて, Stratton は 次式を提出した。

$$
\lambda_{c h} \propto \eta(0) M^{0.75}
$$

(4) Graessley の式: Rouse の緩和時間を $\lambda_{R}$, entanglement の密度を $E\left(=C M /(C M)_{c}\right)$ とすると， Graessley の式は

$$
\frac{\lambda_{c h}}{\lambda_{R}} \propto \frac{1}{1+0.34 E}
$$

$$
3 \text { 解析 }
$$

狭い分子量分布をもつ高分子流体の緩和スペクトル がモデル的に次式で表わされるものとする.

$$
H(\lambda)= \begin{cases}\frac{H_{1}}{1-\delta_{0}} & \lambda_{0} \leqslant \lambda \leqslant \lambda_{1}, \quad \delta_{0}=\frac{\lambda_{0}}{\lambda_{1}} \\ 0 & \text { Otherwise }\end{cases}
$$

この式に抢いて， $\delta=1$ のときは緩和スペクトルは線 スペクトルとなり， $\delta$ 関数によって表わされる。 $\delta_{0}$ が 1 に近く，スペクトルの幅が非常に狭いときは緩和ス ペクトルは線スペクトル的であると仮定して(5)式で一 括的に表現した。

(5)式の仮定のもとで, 零ずり速度に特ける粘度扣よ び第一法線応力差係数 $\psi(0)$ はそれぞれ次式のように 求まる。

$$
\eta(0)=H_{1} \lambda_{1}, \quad \psi(0)=H_{1} \lambda_{1}^{2}\left(1+\delta_{0}\right)
$$

流体の定常状態コンプライアンス $J(0)$, 自然時間 $\lambda_{N}$ を

$$
J(0)=\frac{1}{2} \frac{\psi(0)}{\eta^{2}(0)}, \quad \lambda_{N}=\eta(0) J(0)
$$

で定義すると， $H(\lambda)$ が(5)式で表わされるときは

$$
J(0)=\frac{1}{2} \frac{1}{H_{1}}\left(1+\delta_{0}\right), \quad \lambda_{N}=\frac{1}{2}\left(1+\delta_{0}\right) \lambda_{1}
$$

となる。

すでに発表した構成式から, 非ニュートン粘度は次 式のように求まる。

$$
\eta(\gamma)=\int_{0}^{\infty} H(\lambda) \frac{1}{2 \alpha^{2}}[1-A(\alpha)] d \lambda
$$

ここで

$$
A(\alpha)=\int_{0}^{\infty} e^{-x-\alpha^{2} x^{2}} d x, \quad \alpha^{2}=\frac{1}{2} \beta \lambda \gamma
$$

であり，及は無次元パラメータである. (5), (9)式から $\eta(\gamma)$ を $\delta_{0}$ の種々の值について計算し, 各 $\delta_{0}$ の值に 特祊る換算粘度曲線が， $\delta_{0}=0$ のとさの換算粘度曲線 と $1 / 2 \beta \lambda_{1} \gamma=1$ の点で一致するように重ね合せると Fig. 1 のらになる。粘度曲線の形は $\delta_{0}$ の值によっ て若干変化し，重水合わせは完全ではないが，0.10く $\delta_{0}<1$ の範囲では㟫とんど変化しない，乙たがって， Fig. 1 の横軸を換算ずり速度とみなすことができる.

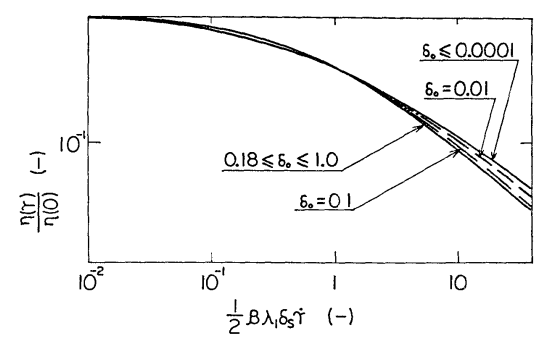

Fig. 1 Superposition of non-Newtonian viscosities calculated from Eqs. (5) and (9)

ここで，重ね合わせのときの移動因子 $\delta_{s}$ は $\delta_{0}$ の関数 であり，

$$
\delta_{s}=1+1.8 \delta_{0}^{0.86}
$$

と表わされる。

社をより直接的に測定可能な量に関係づけられる $\lambda_{N}$ で置きかえると，換算ずり速度は

$$
\beta \frac{\delta_{s}}{1+\delta_{0}} \lambda_{N} \gamma
$$

で表わされる。 $\eta(0)$ の分子量依存性に関しては多く の実測值があり， $\eta(0)$ は $M$ の 3.4 乗に比例する.こ れに対して，J(0) は上り分子量分布の影響を受けや すく, $J(0)$ のデータはそら多くはない. $M$ が臨界分子 量 $M_{c}$ より小さいところでは $J(0)$ は $M$ に比例し， $M$ が $M_{c}$ より大きくなると $J(0)$ の分子量依存性はだん だんと小さくなり，ついには分子量に依存しなくなる。 Prest, $J_{R}^{8}$. の溶融単分散 polystyrene の $J(0)$ の分 子量依存性は次式によって表わされる.

$$
\frac{J(0)}{J_{R C}}=\frac{1.22 E}{1+0.22 E}
$$

ここで， $J_{R C}$ は臨界分子量に和ける Rouse のコンプ ライアンスである。

$\lambda_{c h}$ は

$$
\lambda_{c h}=\beta \frac{\delta_{s}}{1+\delta_{0}} \lambda_{N}
$$

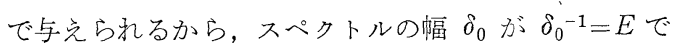
与兄られ，かつ，及は分子量に依存しないものと仮定 すると，(7)，(11)，(12)式から $\lambda_{c h}$ の分子量依存性は

$$
\lambda_{c h} \propto \eta_{0} f, \quad f=\frac{0.34 E}{1+0.34 E}
$$

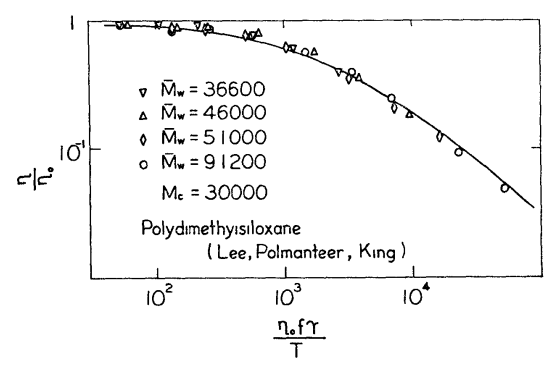

F1g. 2 Superposition of non-Newtonian viscosities of narrow-distribution polydımethylsıloxane ${ }^{9}$. 
で表わされる。この式は Graessley の式と同じ関係 を表わしており，(1)，(2)式で表わされる両極端の領域 を entanglement 密度Eによって連続的に接続してい る. Fig. 2 はが1に比べてあまり大きくない場合の 例として, polydimethylsiloxane 溶融体に(13)式を適 用した例で，重叔合せは満足に行なわれていることが わかる。なお，この図の害線はFig. 1 の $\delta_{0}=1$ のとき の粘度曲線を表わす。

（昭和46年10月21日 第19回レオロジ一討論会にて講演）

\section{参考文 献}

1) Bueche, F, J.Chem. Phys, 22, 1570 (1954).

2) Ballman, R. L., and H M Simon, J Polymer Sci.,
A-2, 3557 (1964).

3) Graessley, W. W., J Chem. Phys., 47, 1942 (1967).

4) Onogi, S, T. Masuda, and K. Kitagawa, Macromolecules, 3, 109 (1970).

5) Stratton, R. A, J. Collord. Interface Sc1, 22, 517 (1966).

6) Graessley, W. W., and L. Segel, Macromolecules, 2, 49 (1969).

7) 中村 良, 吉岡直哉, 木村松弘, 材料, 20，643 (1971).

8) Prest, JR, W. M, J. Polymer Sci., A-2, 8, 1897 (1970).

9) Lee, C. L., K E Polmanteer, and E G. King, J. Polymer Sc1, A-2, 8, 1909 (1970).

\section{(449頁より)}

218. Heat transfer to polymer solutions and melts flowing between parallel plates, W. H. Suckow, P. Hrycak, R. G. Griskey, 401.

\section{Rheological Acta, Vol. 10}

219. The rheology of synovial fluid, P. C. Seller, D. Dowson, V. Wright, 2.

220. Studies on the nature and significance of macromolecular complexes in the rheology of synovial fluid from normal and diseased human joints, G. Nuki, J. Ferguson, 8.

221. Rheological simulation of synovial fluid by a synthetic macromolecular solution, J. Ferguson, G. Nuki, 15.

222. Study of the effect of mechanical working on the rheological properties of some potential artificial lubricants for human joints, M. A. M. A. Younes, P.S. Walker, P.C. Seller, D. Dowson, V. Wright, 21.

223. The rheological properties of saliva, St. S. Davis, 28.

224. Rheological properties of sputum, J.Sturgess, A. J. Palfrey, L. Reid, 36.

225. Histological examination of sputum during rotoviscometry, M. Tekeres, I.C. Geddes, 44.

226. Rheological changes in "native" human blood prior to and during coagulation, G. W. C. Blair, R. H. Matchett, 47.

227. The viscosity of human blood plasma, J. Harkness, R. B. Whittington, 55 .

228. Rheological characteristics of human joints with particular reference to the knee, V. Wright, D. Dowson, R. Goddard, 61.

229. Hydrodynamic disruption of human erythrocytes near a transversely oscillating wire, A. R. Williams, 67.

230. Dynamic mechanical testing of living skin, J. B. Finlay, I. A. Brown, 71.

231. Some mechanical and structural characteristics of connective tissue, J. H. Evans, I. C. Clarke, 77.

232. The rheology of dentai tissue conditioners, M. Braden, 86.

233. Structure and rheology of emulsions stabilised by mixed emulsifiers, B. W. Barry, 96.

234. Rheological changes cccurring during the storage of the system sodium dodecyl sulphate/1-hexadecanol/water, D. B. Mistry, B. Warburton, 106.

235. Rheological properties of white soft paraffin, B. W. Barry, A. J. Grace, 113.

236. Cohesion and tensile strength of bulk solids, T. Eaves, T. M. Jones, 127.

237. A new system of rheological testing at low strains, C. Roberts, 135.

238. A Versatile surface rheometer, E. Shotton, K. Wibberley, B. Warburton, S. S. Davis, P. L. Finlay, 142 .

(458頁へ) 